\title{
NOTAS
}

\section{Los vaqueiros de alzada según las últimas publicaciones}

CÁtedra TOMás, María: La vida y el mundo de los vaqueiros de alzada (Madrid: CIS/Siglo XXI de España ed., 1989), 165 pp. CÁtedra TOMÁS, María: La muerte y otros mundos (Barcelona: Júcar, 1988), 488 pp. Garcí MARTínez, Adolfo: Los va. queiros de alzada de Asturias. Un estudio bistórico-antropológico (Oviedo: Principado de Asturias, Consejería de Educación, Cultura y Deportes, 1988), 400 pp., 59 forgs.

La singularidad de la forma de vida de los vaqueiros de alzada, su marginación histórica y las discusiones sobre su origen, dieron lugar desde el siglo Xvill a un buen número de escritos dotados de muy distinta intencionalidad. En la citada centuria algunos personajes escriben con el afán de demostrar que los vaqueiros pertenecen a una raza distinta, inferior a la del resto de los asturianos, mientras que otros, como Jovellanos, ofrecen pruebas casi palpables de la falsedad de tales afirmaciones. En aquellos años (y también después, aunque en menor medida) quienes atacan desde una falsa erudición a la comunidad vaqueira, lo hacen movidos básicamente por intereses económicos, debido a los inconvenientes que el modo de vida vaqueiro crea entre algunos campesinos y sobre todo a los propietarios nobles.

Durante el siglo XIX (sobre todo en su segunda mitad) los vaqueiros van a interesar especialmente a eruditos, periodistas, folkloristas y estudiosos en general, tanto locales como nacionales y extranjeros. Sus arcaizantes costumbres, la dedicación casi exclusiváa al ganado, su forma de vida seminómada, la rusticidad de sus viviendas y otros muchos rasgos de su cultura (además de sus oscuros orígenes), incitan a la descripción fácil y superficial, al artículo periodístico sensacionalista o a la recogida de rasgos folklóricos aislados. Siguen elaborándose mil y una teorías (casi todas absurdas e incoherentes) sobre sus orígenes, pero ya no es tan evidente esa oposición interesada que se observa en algunos escritos del siglo Xvill.

En 1893, Bernardo Acevedo y Huelves publica la primera edición de la obra que va a considerarse «definitiva» en su época sobre los vaqueiros '. Su trabajo es fundamentalmente una defensa apasionada de esa comunidad de ganaderos y en él rechaza categóricamente cualquier origen «inferior» o «infiel» de los vaqueiros. En 1915 aparece la segunda edición, aumentada, más farragosa que la primera y en la que plantea unas conclusiones mucho menos científicas.

Quizá por la extensión y la popularidad que alcanza la obra de Acevedo, durante la primera mitad de este siglo decae el interés y el número de publicaciones sobre los

1 Los Vaqueiros de Alzada en Asturias (Oviedo: Imp. del Hospicio Provincial, 1893). La editorial G. H. ha publicado una edición facsímil en 1985. 
vaqueiros. Esta trayectoria cambia totalmente desde finales de los años 40 . Varios factores intervienen en el cambio. Desde el ámbito científico es fundamental el impulso dado por Juan Uría y Ríu a los estudios (tanto históricos como antropológicos) sobre los vaqueiros. Sus primeras publicaciones sobre el tema son de los años 20, pero es desde comienzos de los 50 cuando se hace notar con mayor fuerza la importancia de sus aportaciones al tema. Su categórica defensa de la asturianía de los vaqueiros influye sin duda en el cambio de actitud que, al menos en ámbitos oficiales, se observa con respecto a éstos. De ser denostados pasan a ser casi alabados, aunque en realidad van a ser manipulados: la «vaqueirada» de Aristébano es buena prueba de ello.

En cualquier caso, este renovado interés por los vaqueiros trae como resultado la aparición de nuevos artículos, opúsculos y obras que, sin embargo, son escasamente originales. Al margen de los trabajos de Uría y Ríu poco se puede destacar hasta la década de los $70^{2}$. Se inicia entonces una nueva etapa en los estudios sobre la comunidad vaqueira. Los folkloristas seguirán insistiendo en el tema con los mismos patrones de antaño, pero ahora es la casi adolescente antropología social española la que toma cartas en el asunto, y lo hace a través de María Cátedra, quien, desde 1972 (cuando publica su primer artículo sobre los vaqueiros) logra casi la «exclusiva» sobre esta materia. María Cátedra es precisamente la autora de dos de las publicaciones que vamos a comentar ${ }^{3}$, la tercera es obra de Adolfo García Martínez ${ }^{4}$. El planteamiento, las metodología y el enfoque de ambos autores son muy diferentes, al igual que lo son los ámbitos geográficos en los que han trabajado, aunque en los dos casos el objeto de estudio sea la comunidad vaqueira del occidente asturiano. Veremos cuál es el contenido y la orientación particular de cada uno de los trabajos y al mismo tiempo se realizará una crítica y valoración conjunta de los mismos.

Vamos a comenzar por la obra aparecida más recientemente (abril de 1989), la de María Cátedra, La vida y el mundo de los vaqueiros de alzada, ya que se trata de una recopilación de artículos publicados anteriormente 5 , entre 1972 y 1986, y uno más («Etnografía: la descripción de la descripción»), preparado en una primera versión para

2 La bibliografía existente sobre los vaqueiros hasta 1977 puede consultarse en RAMÓN BARAGAÑo, Los vaqueiros de alzada (Gijón: Ayalga, 1977). Otros trabajos posteriores (hasta 1985) se citan en la obra de Francisco FEO PARRONDO, Los vaqueiros de alzada. Estudio geográfico de una comunidad marginada (Oviedo: Caja de Ahorros de Asturias, 1986). De los estudios publicados en las décadas de 1940, 50 y 60 (y exceptuando las obras de Uría y Ríu) apenas se puede destacar algo original, lo más interesante es, quizá, el estudio de Rodolfo SOTO VÁzQuez titulado «El suicidio entre los 'Baqueiros de Alzada' Asturianos», publicado en el Boletín de Estudios Asturianos (1964), LVI, 167-182 y LV, 69-88.

3 La muerte y otros mundos (Barcelona: Júcar, 1988) y la vida y el mundo de los vaqueiros de alzada (Madrid: CIS/Siglo XXI de España, 1989).

4 Los vaqueiros de alzada de Asturias. Un estudio bistórico-antropológico (Oviedo: Principado de Asturias. Consejería de Educación, Cultura y Deportes, 1989).

5 No se han incluido en la recopilación los siguientes artículos:

- «Vacas y vaqueiros. Modos de vida y cultura en las brañas asturianas», en M. CÁTEDRA y R. Sanmartin, Vaqueiros y pescadores. Dos modos de vida (Madrid: Akal, 1979), pp. 9-93.

- «Notas sobre la envidia: los ojos malos entre los vaqueiros de alzada», en C. LISON (ed.), Temas de antropología española (Madrid: Akal, 1976), pp. 9-48.

- «El segundo entierro. Vivos y muertos en las brañas vaqueiras», Historia 16, III, n. $21(1978)$.

- «endito y maldito: categorías de clasificación en el universo vaqueiro», Los Cuadernos del Norte, VII, n." 35 (1986), pp. 70-85.

- «l cuerpo es un sistema», Jano, XXX, n." 717 (1986), pp. 8-24. 
un diccionario de antropología salido a la luz recientemente ${ }^{6}$. Pese al importante espacio de tiempo que media entre la aparición del primero y el último, todos tienen su origen en la investigación desarrollada por su autora entre 1970 y 1972 para conseguir su doctorado por la Universidad Complutense de Madrid. La línea de análisis que los une es «el estudio de la marginación del vaqueiro y las bases ecológico-culturales de este pueblo» (p. VII) y la tesis que pretende demostrar es «que la marginación del vaqueiro no puede ser explicada por sus supuestos orígenes, sino por su ecología, modo de vida y cultura diferente de la de sus vecinos» (p. VII). Reconoce que esta idea ya la había apuntado Uría y Ríu (Jovellanos ya se refería a ello), pero ella pretende demostrarla desde una perspectiva antropológica.

Ya sobre esa primera declaración de propósitos cabría hacer alguna observación. Sin entrar a valorar todavía si la tesis propuesta ha sido o no demostrada, no creemos que la marginación del vaqueiro pueda ser explicada exclusivamente por razones ecológicas, que a su vez condicionarían un modo de vida y una cultura diferentes. Es cierto que la trashumancia, el seminomadismo y el nomadismo ganadero son factores que conducen en gran medida a la marginación o desprecio hacia los pueblos que los practican por parte de los campesinos, pero también lo es que hay comunidades trashumantes (incluso en Asturias) que no se han convertido en «pueblos malditos». Por otra parte, el pretender explicar la marginación porque exista una cultura diferente es un recurso fácil: lo importante es mostrar precisamente cuáles son las razones para que exista esa cultura diferente, y esto es algo que los factores ecológicos no pueden, por sí solos, explicar.

Pero sigamos adelante con el contenido del libro. El capítulo primero ( Etnografía: la descripción de la descripción») trata de introducir al lector en el conocimiento de la etnografía como disciplina. Al margen de algunas ideas sobre la historia de la antropología en España expresadas con excesiva simplicidad, la autora consigue su objetivo, y es especialmente clara e ilustrativa cuando se refiere a los «aspectos humanos y científicos de la etnografía», recordándonos que el antropólogo estudia a seres humanos y, por tanto, debe ser respetuoso en todo momento con esas personas. En la segunda parte de este capítulo, la autora hace una amena e interesante exposición sobre algunos aspectos de su trabajo de campo, especialmente los que se refieren a la entrada en contacto con la comunidad vaqueira, a los distintos «roles» ocupados durante su estancia entre ellos y a la interacción que se produjo. En La muerte y otros mundos (la segunda obra de María Cátedra que vamos a comentar) se había incluido ya esta parte a la que nos estamos refiriendo, en un apartado titulado «El método». En La vida y el mundo de los vaqueiros de alzada no aparece ya bajo ese título. Creemos que la decisión es acertada pues la información que nos presenta la autora no se refiere tanto a la metodología empleada como al proceso de acercamiento, contacto y desenvolvimiento de su estancia entre los vaqueiros. Más cercana a estas cuestiones metodológicas está su referencia a la abundante utilización de citas literales de sus informantes, hecho que justifica por la importancia de mostrar a la gente a partir de su propio lenguaje y por la facilidad y sencillez con que logran exponer ideas que «al antropólogo le llevaría un buen número de páginas explicar».

En el capítulo segundo, «Qué es ser vaqueiro de alzada», se trata de explicar en qué consiste la particularidad del vaqueiro y su mundo, vistos desde la perspectiva del xaldo y desde la del propio vaqueiro. Esta explicación se articula en distintos ámbitos a través de los cuales se evidencia la diferenciación entre ambos. En primer lugar se nos presenta el aspecto mítico de la marginación, pero no analizando las teorías eruditas (o pseudoe-

6 A. AGUIRRE (ed.), Diccionario temático de antropología (Barcelona: PPU, 1989). 
ruditas) sobre el origen de los vaqueiros (esto queda para otro capítulo), sino dando la palabra a los propios xaldos (que presentan sus explicaciones) y a los vaqueiros (que las rebaten).

También interviene en esta discriminación el factor económico: el vaqueiro se acerca a la categoría de xaldo cuanto mayor es su riqueza personal. El mundo de la religiosidad también refleja las diferencias: el vaqueiro es poco practicante de la religión oficial, pero rinde culto fervoroso a San Antonio y a la Virgen del Acebo (fundamentalmente) que está en consonancia con la protección que dan a su ganado estas «divinidades». Por último, apunta la autora las diferencias en el «modo de hablar», que se reflejan en "pequeñas variaciones fonéticas, morfológicas y semánticas» (p. 35). A pesar de que estas variaciones puedan existir, creo que lo más importante en esta diferenciación en el habla reside precisamente en el modo, en la entonación y en el uso de algunas expresiones propias que se ven aumentadas por el modo en que el xaldo percibe el habla vaqueira. Tampoco sirve como hecho particularizador la existencia del sonido [ts] o [tch] entre los vaqueiros. La autora apunta que éstos emplean el proverbio «el que non diga tseite, tsino, tsana non é de la braña" ${ }^{7}$ para distinguirse respecto a los forasteros. Pero ese sonido existe en otras zonas del occidente asturiano e incluso de León (en Laciana, [Tchaciana]), como ya apuntara, entre otros, Acevedo y Huelves. Incluso ese mismo proverbio lo utilizan y consideran como propio los xaldos de la aldea de Barzanallana [Barzanatchana] de la parroquia de Navelgas, en la misma zona estudiada por la autora.

Concluye María Cátedra este capítulo afirmando que «el problema de los vaqueiros es, pues, uno de estratificación sociocultural disfrazado de mito» (p. 44). Además, apunta que «el mayor error cometido al estudiar los vaqueiros ha sido el tomar por historia ortodoxa lo que es en realidad historia popular. Las nociones históricas de la gente rural, sus creencias en torno a la historia y la relación de ésta con otras creencias son parte de la antropología cognitiva, de la filosofía de la historia o de la sociología del conocimiento, y no, como se ha pretendido, de la historia ortodoxa» (p. 44). Esta serie de afirmaciones dan pie a algunas reflexiones. En primer lugar, es obvio que en los orígenes de la marginación del vaqueiro tiene un lugar señalado la estratificación social: el vaqueiro rico puede escapar al desprecio del xaldo. Sin embargo, creemos que por mucho disfraz de mito que haya envuelto a esa jerarquización, ni ésta ni su disfraz explican por completo el hecho. Por otra parte, es cierto que, desde el siglo Xvin hasta hoy, buena parte de los estudiosos que han tratado la cuestión vaqueira han cometido el error de tomar por verdad histórica lo que sólo era fantasía erudita o popular. Pero esto no significa que las nociones históricas de la gente rural (o urbana) queden reducidas a mero objeto de estudio de la antropología cognitiva. La investigación histórica (ortodoxa o heterodoxa) tiene mucho que decir al respecto. No se trata de pretender buscar Troyas reales allí donde el mito nos dice que estuvieron, pues en pocas ocasiones tendríamos la suerte de hallarlas. Lo que sí puede escudriñar el investigador (historiador o etnólogo), utilizando el análisis histórico, es el contexto vital y ambiental que a lo largo del tiempo ha conducido a unas $u$ otras interpretaciones míticas sobre una realidad cualquiera, en este caso sobre la marginación de los vaqueiros. El disfraz mítico puede tener explicaciones que se descubran en el registro histórico, y no porque tuviera realidad material el mito (algo tampoco descartable), sino, porque se dieran unas condiciones muy precisas para su creación.

El capítulo tercero se refiere precisamente al problema de las explicaciones míticas y se titula "Mito e historia de los vaqueiros de alzada». En él se hace un rápido repaso a las distintas teorías expuestas desde el siglo xvill sobre el origen de los vaqueiros y a

7 El que no diga leche, lino, lana no es de la braña. 
los diferentes estudios folklóricos, históricos y etnológicos escritos sobre este grupo social. La autora utiliza como fuente de información la obra de Acevedo y los distintos trabajos de Uría y Ríu. Comenta y valora a su vez los escritos de estas dos máximas autoridades sobre la historia y la etnología vaqueiras y también se refiere a algunos artículos de menor alcance publicados en la segunda mitad del siglo xIX. El trabajo pretende ser una aproximación general al tema, sin profundizar demasiado ni en los manuscritos polemistas del XVIII ni en las obras impresas posteriores. Quizá pueda señalarse que este acercamiento a la historia de la investigación histórica y etnográfica sobre la comunidad vaqueira adolece de lo que se ha venido en llamar "presentismo". Lo que interesa a la autora es mostrar los posibles aciertos y errores que se documentan en esos escritos, el análisis del desarrollo de los estudios sobre los vaqueiros queda en un segundo plano frente a los datos que esas investigaciones aportan. En cualquier caso, esa orientación es comprensible dada la corta extensión del trabajo y los intereses concretos de su autora.

Con el capítulo cuarto, «Ecología cultural de braña y aldea», se entra de lleno en la descripción y análisis de la forma de vida vaqueira. El objetivo es «comparar alternativamente las diferencias fundamentales que existen en el medio en que se desenvuelven aldeanos y vaqueiros» (p. 71), ya que estas diferencias se consideran claves para explicar los orígenes y el mantenimiento de la marginación.

En este artículo se presenta, con croquis incluido, la zona estudiada por la autora, que comprende básicamente las parroquias (y sus aldeas y brañas) de Naraval, Navelgas y Villatresmil, situadas en el concejo de Tineo, aunque algunas brañas pertenecen también a Luarca ${ }^{8}$. Se describe la situación de brañas y aldeas, ocupando las primeras terrenos peores y de mayor altitud (por lo general) que las segundas, aunque algunas aldeas de segundo orden pueden asentarse en terrenos tan malos y poco accesibles como los de las brañas. No obstante, hay un elemento bastante notorio que diferencia a unas y otras: en las brañas las viviendas aparecen siempre separadas entre sí.

Ya dentro de la braña, se describe la vivienda y se evalúan mínimamente los diferentes terrenos que disfrutan (tierra, prado y monte), comparándolos con los existentes en la aldea. En ésta, el porcentaje de tierra de cultivo es bastante superior al de la braña, disminuyendo el dedicado a prado y monte.

Otra característica diferenciadora de braña y aldea es el sistema de separación de propiedades. En la braña se levantan paredes de piedra, en la aldea se utilizan casi exclusivamente mojones, aunque últimamente también comienzan a verse paredes divisorias, entre otras razones por la extensión de los prados. El trabajo se completa con la descripción de las distintas tareas desempeñadas en la braña y la aldea. Arriba, en la braña, lo principal son los pastos y la recogida de la hierba, con muy escasa dedicación a los cultivos. Abajo, en la aldea, lo fundamental es el policultivo, sólo la mitad (o menos) del terreno cultivado se dedica (o se dedicaba hasta el auge de la ganadería lechera) a alimento para el ganado. La diferente meteorología también condiciona cultivos y labores. Por todas estas circunstancias es obvio que la importancia del ganado vacuno es fundamental en la braña, siendo la vaca «roxa» el tipo de ganado que mejor se adapta a las condiciones de aquélla.

8 En el croquis de la página 73 se ha deslizado algún error en la clasificación de los núcleos de población. Silvallana y Relloso se identifican como brañas de alzada y son de invierno; por el contrario, Bustellán y Las Tabiernas se presentan como brañas de invierno y son brañas de alzada. Por otra parte, también se puede apuntar que calificar a Naraval como aldea principal y a Navelgas simplemente con aldea, no concuerda con el desarrollo poblacional actual de ambas, aunque en el registro histórico la primera tuviera mayor entidad que la segunda prácticamente durante todas las épocas. 
Todos éstos son los rasgos y condicionamientos que caracterizan las diferentes estrategias de adaptación de brañas y aldeas. En toda la exposición, clara e ilustrativa, hay, sin embargo, un aspecto que no se menciona y es el hecho de que la comparación entre la ecología de braña y aldea se hace teniendo como referencia las brañas de invierno, no las de alzada. Estas últimas son ahora sólo tres en la zona, pero hubiera sido conveniente hacer una diferenciación tripartita al estudiar tanto la ecología como el hábitat de la zona: brañas de invierno, brañas de alzada y aldeas. También podemos apuntar que, al no hacerse un análisis complementario de carácter histórico, no se documentan las posibles variaciones que, tanto en las formas de poblamiento como en los sistemas económicos, hayan podido producirse al convertirse las brañas de invierno en poblaciones estantes (como son ahora la mayoría) y al dejar de ocuparse enteramente durante el verano las brañas de alzada.

Se apunta la idea de que hasta el siglo XVIII la mayor parte de la población de las brañas de invierno alzaba totalmente su morada durante los meses de verano, ocupando los pastos de alta montaña a cambio de un determinado canon económico. Sin embargo, desde la centuria citada (o incluso antes) las familias que disponían de más y mejores tierras en las brañas de invierno permanecían en éstas durante el verano, enviando el ganado a los puertos con algunos miembros de la familia o al cuidado de algún individuo asalariado.

Hasta hace treinta o cuarenta años el sistema principal de trashumancia consistía precisamente en llevar el ganado a esos puertos altos (en los límites con la provincia de León), aunque en pocos casos alzaba toda la familia, encargando varias de éstas el cuidado del ganado a un «brañero» o «vaqueiro». El traslado de los animales lo realizaban sus dueños en grupo, dando lugar a una animada comitiva que los vaqueiros recuerdan con agrado. El viaje, además de proporcionar alegría y diversión, servía para realzar el sentido de grupo y dar fe de la buena calidad del ganado frente a los xaldos de las aldeas que atravesaban. A principios de los años 70 , cuando realiza su trabajo la autora, sólo tres casas enviaban sus ganados a Cangas de Narcea, y lo hacían en camiones alquilados.

El sistema de trashumancia a grandes distancias casi ha desaparecido totalmente pero aún se conserva una variante menor que es la de alzar la morada a las brañas de verano de los puertos del interior del concejo, en concreto a las tres brañas de alzada existentes: Los Corros (Luarca), Bustellán y Las Tabiernas (Tineo). Cátedra señala que eran 58 las casas que trashumaban procedentes de doce brañas, de las que sólo cuatro alzaban casi totalmente ${ }^{9}$. A diferencia de la situación existente en los puertos de Cangas, en las

9 En las tres brañas citadas, una parte de la población permanece estante durante todo el año. En Bustellán esta sedentarización ha alcanzado cotas muy altas, al igual que ha crecido considerablemente el tamaño de las edificaciones, tanto las dedicadas a vivienda como a establo. En realidad, hoy (1989) el panorama ha cambiado mucho en la mayoría de las brañas desde los años en que desarrolló su trabajo de campo $M$. Cátedra. El asfaltado de carreteras, la extensión de maquinaria agrícola de todo tipo, ordeñadoras, enfriadoras para la leche, etc., han variado notablemente la forma de vida vaqueira. Las brañas de alzada también se han visto afectadas por estas innovaciones pero han respondido de forma diferente. En Las Tabiernas, el envejecimiento y el éxodo de la población en sus correspondientes brañas de invierno, supusieron el abandono de la alzada y la venta o arriendo de los prados y viviendas. Actualmente hay un buen número de casas vacías, las que aún no se han derrumbado han sido compradas o tomadas en arrendamiento por los que todavía acuden, quienes las utilizan como pajares o cuadras. Lo mismo ha ocurrido con los prados o campas, lo que redunda en una mayor disponibilidad de alimento para el ganado de las casas que residen todo o parte del año en Las Tabiernas. En Bustellán pudo haber ocurrido inicialmente algo parecido pero dada su mayor extensión y por tanto su mayor disposición de prados, la despoblación ha 
brañas de alzada citadas los vaqueiros cuentan siempre con una pequeña propiedad, *consistente en un número de prados, una vivienda y frecuentemente porciones de monte» (p. 112). También es significativo que en estas brañas nadie se dedique al cuidado asalariado de ganado ajeno.

En este sistema de trashumancia a cortas distancias, «la frecuencia de los viajes a la alzada, la duración de la estancia en ésta, así como el número de trashumantes de cada casa varía también dependiendo del tamaño de ambas propiedades y de la familia» (p. 113). No obstante, lo que ahora se destaca es que en este sistema el número de viajes se multiplica, y desde marzo a noviembre pueden darse seis u ocho cambios de residencia para lograr un mejor aprovechamiento de los prados. Por esta circunstancia los vaqueiros se refieren a esta forma de vida como los «dos fuegos» o las «dos vidas».

La trashumancia trae consigo ventajas e inconvenientes. Puede servir para aliviar tensiones familiares y matrimoniales (por la separación de los miembros), pero también da origen a problemas con las aldeas-parroquias por la media vecindad. Por otra parte, si históricamente la trashumancia ha sido despreciada como forma de vida inferior, entre los propios vaqueiros la sedentarización de buena parte de ellos provoca escisiones internas. Muchos desean abandonar la trashumancia, pero sus escasas posibilidades económicas se lo impiden y esto puede dar lugar a la marginación dentro de la marginación. No obstante, también se ha de advertir que desde las aldeas (especialmente las de menor entidad) se observa un proceso de acercamiento a la forma de vida vaqueira, no por la práctica de la trashumancia, sino por la potenciación de la explotación ganadera, debido al auge de la venta de la leche.

Hasta aquí algunos de los datos aportados por la autora que describen de manera acertada las características de la trashumancia en el momento y zona estudiados. Se pueden señalar, no obstante, ciertas lagunas que se refieren a la forma de vida vaqueira anterior a la situación estrictamente contemporánea a la realización del estudio. Las breves referencias a los puertos de Cangas del Narcea dejan numerosos interrogantes en el aire. En primer lugar, no se localizan las zonas ocupadas, el sistema de aprovechamiento y propiedad de los pastos, las formas de ocupación del espacio, etc. ${ }^{10}$. Cuando se refiere a la subida a los puertos, define a éstos como «espacios ajenos, desconocidos y hostiles» (p. 107). Esta hostilidad sería cierta y evidente desde el momento en que las familias dejaron de alzar totalmente sus moradas, pero antes seguramente no. Adolfo García, en su estudio sobre los vaqueiros de Salas, Belmonte y Somiedo, se refiere precisamente a los puertos altos de Somiedo como el lugar de residencia preferido, frente a las brañas de invierno.

sido mucho menor, e incluso se puede decir que hoy ha aumentado el número y poder económico de los propietarios.

Otro factor que interesa destacar es que el aumento de la cabaña ganadera (especialmente lechera) ha llevado a la extensión de las «cavadas", es decir, a la transformación del monte público en campas y prados. Este proceso no ha sido exclusivo de las brañas vaqueiras ya que en terrenos colindantes a ellas los aldeanos de Folguerúa, por ejemplo, han realizado igualmente «cavadas». También algunos xaldos (de Villatresmil especialmente) han comprado prados en Las Tabiernas; no suben con el ganado, siegan la hierba y la bajan a sus aldeas.

${ }_{10}$ Los principales puertos de alzada eran Los Llanos, La Filtrosa y Soldepuesto (en Cangas de Narcea), además de otros varios en el concejo leonés de Laciana. Apuntemos también que ha existido algún caso de braña teóricamente invernal pero que ha sido utilizada como alzada por vaqueiros de brañas menos altas y más cercanas a la marina. Esto ocurrió en Concellín, braña del concejo de Tineo pero muy cercana a Pola de Allande, donde al menos dos vecinos de Businán (Tineo) disponían de casa y prados y allí trasladaban su ganado y su residencia durante buena parte del año. 
Tampoco se hace referencia alguna al papel desempeñado por las brañas de alzada de Tineo y Luarca cuando estaba extendida la trashumancia a los puertos de Cangas.

Obviamente tales cuestiones no pueden estudiarse desde una perspectiva exclusivamente etnográfica, como es la que utiliza María Cátedra, sería necesario recurrir a fuentes documentales. Con esto no quitamos ningún mérito al trabajo realizado por la autora, pero sí apuntamos que el presente etnográfico no puede explicar por sí mismo el pasado de un pueblo. En el caso de los vaqueiros la necesidad de completar el estudio antropológico con el análisis histórico es fundamental, pues sólo de ese modo podemos comprender los procesos de cambio y las circunstancias que pueden haber incidido en el desarrollo de sendas conciencias marginal y marginadora, características de vaqueiros y xaldos, respectivamente.

Y con esto entramos en el último capítulo, el sexto, de la obra, titulado «Las vacas también son buenas para pensar». Se trata del trabajo más «antropológico» del libro, no en vano se encabeza con una extensa cita de Fl pensamıento salvaje de Lèvi-Strauss, y tiene como objetivo «explorar la manera en que el grupo humano interacciona con su entorno a un nivel más elevado de la estricta base económica, en el plano mental» (p. 131). Se valoran de este modo las homologías existentes entre vaca y mujer en el mundo vaqueiro: vaca «roxa»-mujer vaqueira, frente a vaca aldeana (no «roxa»)-mujer aldeana; se estudia el importante papel desempeñado por la vaca en la socialización del individuo vaqueiro; el ciclo vital de la vaca y el elemento emocional que rodea a su muerte dentro de la casa vaqueira; y, por último, el «rol» desempeñado por la vaca como elemento intermediario entre vivos y muertos y su capacidad para presentir la muerte de los humanos.

Todo este mundo de categorías, relaciones, valores y sentimientos que se mueve alrededor del ganado vacuno (concretamente del «roxo») es fácilmente constatable entre la comunidad vaqueira. La vaca, la mujer y la muerte son, quizá, los tres ejes fundamentales de su existencia; no es, por tanto, extraño que aparezcan interrelacionados y sirvan para conceptualizar múltiples aspectos del mundo vaqueiro.

Con el anterior planteamiento, la mayor parte de la información contenida en el artículo y su propio título responden a una misma idea: la vaca es la base económica de los vaqueiros, por ello - y además - también resulta fundamental en la elaboración de conceptos e ideas, "también es buena para pensar». Ese adverbio, «también», es el que marca la clave. Por tanto, no parece acertado incluir citas de Lèvi-Strauss para justificar o dar validez al tipo de estudio realizado, y menos aún recoger la idea de este autor según la cual «se comprende que las especies animales no sean elegidas por ser buenas para comer, sino por ser buenas para pensar» (p. 157). La idea que nos presenta la. autora es, si no opuesta, al menos claramente diferente a la defendida por el antropólogo francés. No hace falta ser estructuralista para sostener que la vaca (en este caso) genera todo un cúmulo de conceptos y categorías de identificación y diferenciación social y ello no conduce a la conclusión de que se elija precisamente a la vaca por su capacidad generadora de conceptos y no por el potencial energético que aporta. En este sentido, las críticas que Adolfo García hace a María Cátedra son solamente aceptables en parte ${ }^{11}$. Es cierto que este acercamiento al estructuralismo se aleja de la reivindicación ecológica, casi determinista, sobre el origen y desarrollo del modo de vida vaqueiro, pero también lo es que una lectura objetiva de este capítulo que comentamos nos lleva a la conclusión de que su autora parece haberse incluido a sí misma en una corriente en la que en realidad no se ha embarcado, o al menos no demuestra haberlo hecho con claridad.

11 op. cit., pp. $37-38$. 
Esa orientación antropológica, cercana al estructuralismo, aparece con mayor notoriedad en algunos de los apartados de la segunda obra de María Cátedra que vamos a comentar; nos referimos a La muerte y otros mundos ${ }^{12}$. La investigación sirvió a su autora para doctorarse en antropología por la Universidad de Pennsylvania. La información que aparece en el libro fue recogida fundamentalmente durante 1974 y 1975 , aunque hay algún dato anterior y posterior a esas fechas.

Al encararnos con esta obra lo primero que nos llama la atención es su grosor, el reducido tipo de letra y, en definitiva, la densidad enorme del trabajo. Son en total 488 páginas, lo que la convierte en la investigación de mayor volumen publicada acerca de los vaqueiros. Otro rasgo notorio es la ausencia de cualquier tipo de ilustración, incluidos mapas y planos ${ }^{13}$. Este rechazo de la imagen puede tener su justificación en el deseo de la autora de respetar la intimidad de sus informante y de no revelar la identidad concreta de las brañas a las que pertenecen. Este planteamiento es muy respetable y digno de ejemplo. Sin embargo, hubiera sido aconsejable incluir, al menos, los croquis que se reproducen en la obra comentada anteriormente, pues la única referencia al espacio geográfico es que se sitúa entre los concejos de Tineo y Luarca. Incluso se mantiene oculto el nombre de las entidades de población, cuando éstas ya son conocidas de artículos publicados en años anteriores.

Menos justificada está la no inclusión de ningún tipo de imagen sobre aspectos no relacionados con la identidad de los vaqueiros informantes y sus respectivas brañas, es decir, todos aquellos elementos pertenecientes a la cultura material que no revelan esa identidad individual. Creo que esta ausencia se explica tanto por el carácter antropológicosocial de la investigación - y de la formación de la autora - como por razones editoriales.

Pero dejemos ya los aspectos formales de la obra y entremos en su contenido. El objeto de la investigación es obvio: se estudia el hecho biológico y sociocultural de la muerte entre los vaqueiros. La autora, siguiendo a R. Hertz y A. Van Gennep, considera que la muerte «no es un acto instantáneo sino un largo proceso, una transición a un estado diferente de ser» (p. 31). Por tanto, el estudio queda articulado en tres partes: I, «El camino hacia la muerte» (la enfermedad); II, «La muerte»; III, «El más allá».

En las páginas introductorias se incluye un apartado titulado «El método", al que ya nos hemos referido al comentar la obra anterior. Ya apuntamos entonces cómo al publicarlo por segunda vez en este último trabajo ( $L a$ vida $y$ el mundo...) no se presenta bajo el título citado. Decíamos que esto nos parecía acertado porque, más que de una reflexión metodológica, se trata de una exposición de las interesantes circunstancias que rodean su introducción e interrelación con los vaqueiros. A continuación se presenta «el problema», es decir, el objeto del estudio, en sólo cinco páginas. Se hacen algunas referencias a los logros y carencias en el estudio antropológico de la muerte y se apunta que, en general, los antropólogos no han estudiado la muerte como el continusm que comienza antes y permanece después del momento preciso de la defunción. En relación con esto, quizá hubiera sido aconsejable realizar una reflexión algo más profunda sobre el estudio de la muerte desde la antropología.

La enfermedad y todo to relacionado con ella, se analiza desde cuatro coordenadas diferentes: 1) en su relación con el medio natural, donde se representan las categorías

12 Editorial Júcar, Barcelona, 1988.

13 En el comienzo de la introducción (p. 18) se hace referencia (y se deja espacio) a una figura en la que se deberían representar los concejos tradicionalmente vaqueiros, pero el plano no se publica. También en la página 290 la autora informa de haber realizado mapas con la procedencia de acompañantes a entierros, que tampoco se incluyen, ya que parece no considerarse necesario. 
de bendito y maldito; 2) desde el cuerpo de la persona, al que se considera como un sistema cuyo desequilibrio refleja la enfermedad; 3) a través del análisis de la envidia, que genera unos tipos concretos de enfermedades, que afectan fundamentalmente al mundo infantil y al ganado vacuno; 4) mediante el examen de los distintos especialistas de la curación.

En el estudio de la enfermedad y en concreto de las relaciones entre el hombre y el medio, los conceptos de bendito y maldito y el análisis e interpretación de mitos y leyendas aparecen claramente organizados bajo el esquema estructuralista de los opuestos complementarios, que puede ser excesivamente rígido en algunos casos. Sin embargo, el desequilibrio del sistema corporal, la envidia y los especialistas de la curación se estudian e interpretan desde una óptica claramente funcionalista. Esto no supone ausencia de claridad o disparidad en la orientación teórica, simplemente se adoptan posiciones teóricas distintas para explicar los problemas de la manera más convincente. En esta primera parte destaca el fenómeno de la envidia, o «los ojos malos», a la que María Cátedra considera un claro fenómeno funcional, ya que «sanciona las diferencias económicas dentro del grupo y promueve una mayor igualdad social: es el precio que debe pagar el rico por su excesiva riqueza y el mecanismo que impele al pobre para serlo menos» (p. 140). Semejante carga funcional poseen los especialistas de la curación (desde el médico oficial a la «adivinona»), cada uno capaz de actuar contra la enfermedad de acuerdo al distinto origen de ésta.

La muerte (segunda parte) se aborda en su doble faceta de muerte natural o muerte violenta (suicidio y, en menor medida, homicidio), analizándose además el entierro. Quizá sea el tema del suicidio el que resulte más interesante de esta segunda parte. La autora se plantea su estudio tomando como fuente de información (además de los datos del trabajo de campo) las estadísticas y valoraciones publicadas en 1965 por Rodolfo Soto Vázquez ${ }^{14}$. El cargo de «Juez de Primera Instancia e Instrucción» del concejo de Luarca le permitió al autor comprobar que el porcentaje de suicidios entre los vaqueiros era muy superior al del resto de asturianos y que también era mucho más alto el porcentaje de mujeres vaqueiras suicidas que el que reflejaban las estadísticas para las mujeres del resto de la región y el Estado. Soto Vázquez apunta que las causas de esta situación pueden encontrarse en el aislamiento y en cierto complejo de inferioridad camuflado de "falsa superioridad y espectacular exhibicionismo» (p. 216).

María Cátedra, pese a la calidad y seriedad científica del trabajo de Soto Vázquez, considera que su investigación es externa, realizada «desde fuera». Ella pretende hacer sus consideraciones «desde dentro», «según la óptica de los propios actores» (p. 217) (excluidos, obviamente, los propios suicidas). El método empleado ha sido la encuesta oral propia del trabajo de campo y el seguimiento directo de algún caso de suicidio ocurrido durante su estancia en las brañas. El número de casos estudiado es muy alto, y muy detallada la descripción de las circunstancias que los rodean. Sin embargo, las conclusiones a las que llega la autora creemos que no explican ese elevado porcentaje de suicidios que se da entre los vaqueiros en comparación con el resto de la población asturiana. Las causas que llevan al suicidio son, en la mayoría de los casos, según María Cátedra, los siguientes: 1) evitación de castigos judiciales cuando el individuo puede ser o ha sido condenado por la justicia; 2) evitar sufrimientos cuando se padece una enfermedad grave; 3) dificultades familiares y conyugales originadas por «el sistema de herencia y su correspondiente distribución de roles dentro de la casa” (p. 226); 4) el «aburri-

\footnotetext{
14 Op. cit. en nota 2.
} 
miento», que incluye variadas situaciones, como enfermedad, falta de dinero, disgustos, nervios, soledad, etc.

Todas las circunstancias apuntadas pueden considerarse suficientes para explicar la mayoría de los casos de suicidio documentados. Sin embargo, lo que permanece sin respuesta es la interpretación de esa diferencia porcentual tan significativa que sitúa a los vaqueiros muy por encima de los restantes asturianos en las estadísticas del suicidio. En la mayor parte del occidente asturiano numerosas aldeas xaldas comparten medios ecolbgicos semejantes a los que rodean a las brañas de invierno; también el sistema de herencia y la organización de los «roles» domésticos resultan coincidentes. No podemos olvidar, por otra parte, que la práctica totalidad de la comunidad vaqueira objeto de investigación es sedentaria y reside durante todo el año en las brañas de invierno. En el estudio del suicidio, como en el de otras cuestiones que apuntaremos, no se considera ni el hecho de la trashumancia a los puertos altos de Cangas ni los traslados a las brañas de alzada actuales. Sería conveniente, por ello, documentar en el registro histórico tanto la posible incidencia de esos cambios de residencia en relación con lo casos de suicidio, como retrotraer la investigación a etapas anteriores (si es posible) para comprobar los procesos de cambio.

Algo semejante podríamos apuntar con respecto al capítulo dedicado al enterramiento. Nuevamente la descripción etnográfica es de una enorme calidad, incluyendo documentación sobre un buen número de casos. Pero hay hechos, como la muerte en las brañas de alzada (a la que se refiere un informante en la página 301) que no se estudian, no ya en lo refrente al entierro, sino a cualquier otro aspecto. El banquete ofrecido en los entierros es otro acontecimiento tratado con detalle. Esta comensalidad es considerada por la autora como el aspecto «más llamativo» de las ceremonias de enterramiento. Sin embargo, también se reconoce que dicha costumbre fue praticada igualmente por los aldeanos. Al no accederse al registro histórico, quedan sin explicar las posibles diferencias existentes, cómo fue el proceso de su desaparición entre los xaldos y cómo encajó esto con su permanencia entre los vaqueiros.

Parecidas observaciones podemos hacer acerca del «cabo de año» o segundo entierro y las comidas que nuevamente se ofrecían transcurrido un año, aproximadamente, del entierro; costumbre observada tanto por los vaqueiros como por los xaldos. En este caso, la información que se nos ofrece no es demasiado abundante y parece escasa en relación con la importancia del fenómeno estudiado. También en esta ocasión la comparación entre los actos realizados por xaldos y vaqueiros y las referencias históricas, contribuirian a un conocimiento más exhaustivo de esa celebración.

Las referencias al cabo de año sirven de introducción a la parte tercera de la obra, donde se estudian los espíritus y los santos. Como en el resto del libro, aunque quizá ahora con mayor énfasis, esta parte se elabora recogiendo las vivencias y sentimientos de los vaqueiros ante fenómenos tan complejos y (relativamente) misteriosos como son los espíritus y las divinidades. Las numerosas (y en muchos casos extensas) citas literales recogidas de las conversaciones con los informantes son la pieza clave del relato ${ }^{15}$. Se

15 Una de las características de los trabajos publicados por María Cátedra (y especialmente del que ahora comentamos) es el uso abundante de citas literales tomadas a los informantes. Ciertamente son escasos los antropólogos españoles que siguen esta línea metodológica en la publicación de sus investigacions y convendría tenerlo en consideración, ya que esas citas permiten un acceso mucho más directo a las formas de pensamiento de los individuos estudiados. También es importante observar, como apunta la autora, que ese material oral puede ser utilizado como fuente de información por otros investigadores. No obstante, nos atrevemos a hacer una observación al respecto. En La muerte y otros mundos el uso de esas citas resulta, 
nos ofrece un considerable cúmulo de experiencias personales sobre contactos, visiones o percepciones de espíritus de vivos y muertos y sobre las especiales relaciones que mantienen algunos animales con esos espíritus. Estos relatos vivenciales son, en la mayoría de los casos, más ilustrativos sobre las creencias vaqueiras que las definiciones sobre conceptos dadas en respuesta a las preguntas de la autora, respuestas que en algunas ocasiones pueden dar lugar a elaboraciones teóricas no coincidentes con el sentimiento o creencia auténticos.

En el capítulo sexto y último («Los santos») se estudia «el hábitat de los espíritus y las interrelaciones de los difuntos y los santos en la cosmología vaqueira» (p. 385). Ese lugar al que acuden los espíritus está rodeado de ambigüedades y escasa concreción en la mente vaqueira. Sobre lo que sí existe una idea clara y precisa es acerca de los «santos» esenciales de su religiosidad: San Antonio, la «Santa» (Virgen) del Acebo y las Ánimas. El capítulo concluye con el estudio de los intermediarios humanos que actúan para comunicar al vaqueiro con sus santos cuando este contacto no puede realizarse directamente; sacerdotes y rezadoras son los principales.

Las conclusiones finales del estudio se presentan bajo el título «El estudio de la muerte». Aquí se retoma la idea de la identidad vaqueira como grupo social diferenciado. El argumento principal que defiende la autora es que el estudio de la muerte entre los vaqueiros «nos ha permitido vislumbrar una compleja y sofisticada cosmología, bastante diferente de la que se conoce sobre otros españoles» (p. 472). Esto puede ser cierto, pero también lo es que no existen estudios en profundidad sobre la religiosidad de comunidades campesinas asturianas que podrían confirmar o desmentir ese particularismo, sobre todo en lo que se refiere a la zona occidental de Asturias, cuyos aldeanos comparten con los vaqueiros numerosos rasgos culturales y creencias. La citada afirmación de la autora, que acabamos de comentar, se completa con una segunda; «los vaqueiros son simplemente asturianos que practican la trashumancia» (p. 473). De la conjunción de ambas ideas - aparentemente contradictorias - resulta la necesidad de explicar de dónde proviene el sistema de ideas y creencias vaqueiro.

Antes de entrar en el comentario de estas explicaciones conviene que nos refiramos a la idea de que la trashumancia es la única característica que distingue a los vaqueiros respecto a los demás asturianos. Este es un planteamiento que se ha venido utilizando para rechazar la hipotética particularidad étnica de los vaqueiros. El argumento fundamental que lo sustenta es que la única, o más importante, razón que explica la marginación y el desprecio hacia la comunidad vaqueira proviene de su sistema de aprovechamiento económico, al que la dedicación casi exclusiva al ganado vacuno, la trashumancia y la ocupación de hábitats aislados, le han conferido una imagen muy particular. Esta argumentación parece no tener en cuenta que en Asturias ( $y$ en otros lugares del norte peninsular) han existido y existen ganaderos trashumantes que no han sufrido una marginación semejante a la del vaqueiro y que tampoco han dado origen a la formación de un grupo social diferenciado. Quizá la dedicación a la arriería haya influido de manera mucho más determinante en el desarrollo de esa marginación, igual que ha ocurrido entre los maragatos.

Para terminar, nos resta hacer referencia a las citadas explicaciones que aclararían la aparente contradicción de la riqueza de la cosmología vaqueira si se asume que se trata

quizá, demasiado determinante en todo el esquema de la obra, aunque la autora señala que es precisamente eso lo que había pretendido. Pese a todo, los numerosos casos y citas recogidos dejan poco espacio para la reflexión sobre las mismas; además esta propia reflexión aparece ya condicionada por el relato de los informantes, quedando un margen bastante escaso para la observación analítica de la autora. 
simplemente de asturianos que practican la trashumancia. María Cátedra apunta en primer lugar que «su coherente visión del cosmos, la noción del espíritu, sus actitudes y valores sobre los animales, etc., son superviviencias arcaicas de ideas que alguna vez fueron comunes en la cultura alpina o indoeuropea que han sobrevivido entre los vaqueiros* (p. 437). Esta interpretación no aclara prácticamente nada ni seguramente puede comprobarse; por ello la autora se refiere a otra más plausible, y es que, «debido al mismo aislamiento de los vaqueiros gradualmente han inventado su cosmología, adaptando ideas de la cultura exterior - las Ánimas del Purgatorio o los Santos-, de manera que satisfagan sus necesidades, sin estar controladas o corregidas por maestros, curas o inquisidores» (p. 473). Realmente, aunque esta segunda hipótesis sea más concreta y se aleje del socorrido indoeuropeísmo, lo cierto es que tampoco explica mucho y la autora reconoce que lo único que puede hacer es plantear al problema y «dejarlo sin respuesta». Por nuestra parte podemos hacer un par de observaciones. En primer lugar, cabría la posibilidad de replantear el pretendido aislamiento secular de los vaqueiros, sobre todo si tenemos en cuenta lo extendido de la arriería (y, por tanto, los contactos con el exterior). Por otra parte, insistimos en que sólo la comparación con la cosmología de los aldeanos del occidente de Asturias y de otras comunidades de la Península, podría ofrecer algo de luz sobre el problema, lo que ocurre es que todavía están por hacer estos estudios.

Finalmente, no queremos dejar de destacar (y subscribir) la llamada que se hace desde el texto comentado a la realización de investigaciones históricas sobre «cosmologías y visiones del mundo en la época medieval y moderna" (p. 473), llamada que nosostros enfocaríamos muy especialmente hacia el estudio de aquellas comunidades analizadas por antropólogos pero sobre las que carecemos de esa visión histórica, o mejor, etnohistórica, imprescindible.

Es precisamente ese enfoque histórico el que predomina en la tercera y última publicación que vamos a comentar, cuyo autor es Adolfo García Martínez ${ }^{16}$, en la que se estudia la comunidad vaqueira de los concejos de Salas, Belmonte y Somiedo. Resulta casi paradójico, o cuando menos llamativo, el hecho que acabamos de consignar. Efectivamente, pese a que el autor se define como antropólogo (seguidor del materialismo cultural) y aunque reconoce que por no ser historiador ha tenido problemas en la investigación, algo más de la mitad de las páginas de su obra (excluidos los apéndices) corresponde al análisis histórico del fenómeno vaqueiro y las restantes están notablemente condicionadas por ese enfoque histórico. Dejamos constancia de este hecho, no para criticarlo, sino todo lo contrario, para destacarlo y hacer un llamamiento en defensa de la utilización conjunta y complementaria de las metodologías histórica y antropológica que tanta falta nos hace.

En el prólogo se presentan algunas de las ideas centrales de la investigación: 1) «no todos los trashumantes son vaqueiros de alzada ni todas las brañas son vaqueiras, sino que los vaqueiros y sus brañas son un subgrupo en el marco de tales fenómenos y un acontecimiento mucho más reciente que el de la trashumancia y las brañas»; 2) «sus peculiaridades socio-culturales no pueden explicarse de otro modo que en relación al proceso de colonización y de explotación de sus espacios»; 3) «los vaqueiros de alzada constituyen un fenómeno socioeconómico íntimamente ligado a la gran propiedad nobiliaria, hecho que explicaría el porqué se originó y se consolidó en unas determinadas zonas de Asturias y no en otras ecológicamente similares»; 4) «tampoco el recurso exclusivo a los factores ecológicos para demostrar su origen y sus peculiaridades constituiría una prue-

16 Op. cit. en nota 4. 
ba válida»; 5) «los vaqueiros de alzada no parecen ser un grupo arcaico, ni por su antigüedad ni por su forma de vida" (p. II).

Según el autor, los vaqueiros se constituirían como grupo social diferenciado entre finales del siglo $\mathrm{XV}$ y finales del XVII, «desde mediados del XVI y a lo largo del XVII los vaqueiros van haciéndose dueños de una serie de tierras y de una cabaña ganadera muy numerosa; a principios del siglo Xvill comienzan a redimir los dominios jurisdiccionales (...) y finalmente, a finales del XIX y primer cuarto del $\mathrm{xx}$ compran los espacios no cercados» (p. II). El modo de vida y la economía vaqueiras se completarían con la venta de algunos excedentes ganaderos y con la práctica de la arriería y la trajinería.

Pasemos ya a observar cómo se desarrollan esas ideas a lo largo del trabajo, que aparece dividido en dos partes, la histórica ( «En torno a los orígenes, formación y constitución de los Vaqueiros de Alzada como grupo social diferenciado») y la etnográfica («El modo de vida de los Vaqueiros de Alzada. Niveles de adaptación»). El capítulo primero de la primera parte aborda el estado de la cuestión. Hace un muy breve repaso a las hipótesis y estudios sobre los vaqueiros en los siglos XVIII y XIX, deteniéndose algo más en Jovellanos y Acevedo. Sobre las investigaciones publicadas en el siglo XX hace una evaluación crítica más concreta. Destaca los trabajos de Juan Uría y Ríu y el rechazo de éste con respecto a la teoría étnica sobre los orígenes de los vaqueiros. Sin embargo, considera que sus trabajos son básicamente un punto de partida para posteriores investigaciones históricas y antropológicas. En relación a las ideas manejadas por Uría, A. García asegura que los lugares habitados por los vaqueiros son pueblos y no brañas (p. 33). Las brañas son «anteriores a la aparición de los pueblos de vaqueiros y de los vaqueiros mismos» (p. 34), eran los pastos a los que acudían los ganaderos en momentos concretos del año, dentro de un esquema socioeconómico de trashumancia de valle, que más tarde se transformarían en pueblos vaqueiros mediante la construcción de cerramientos, viviendas y otras estructuras complementarias.

Tras Uría y Ríu se pasa revista a las investigaciones de María Cátedra. A. García destaca la gran calidad del trabajo etnográfico de Cátedra, pero le plantea una serie de inconvenientes. El primero atañe a la zona elegida (en los concejos de Tineo y Luarca) cuyos habitantes vaqueiros son casi totalmente sedentarios desde hace años. Además, en estas tierras apenas existió la trashumancia de valle no vaqueira, lo que hace menos rico y complejo el estudio del problema. También critica un aspecto fundamental y es el carácter ahistórico de la obra de Cátedra, que impide comprender el desarrollo de la comunidad estudiada. Otra hipótesis que no comparte es que la ecología cultural explique por sí misma la formación del grupo social vaqueiro, pues de ser esto cierto deberían haber surgido comunidades semejantes en otras zonas de Asturias en las que también se ha practicado la trashumancia ${ }^{17}$.

Los últimos párrafos sobre el estado de la cuestión están dedicados a un trabajo de carácter histórico de Margarita Cuartas Rivero sobre «Dominio señorial y vaqueiros de alzada» ${ }^{18}$, que aporta importantes argumentos históricos sobre los vaqueiros pero cuyas conclusiones no coinciden con las de A. García.

Con el capítulo segundo se entra ya en materia, trata «El desarrollo de la ganadería en Asturias durante los siglos XI, XII, XIII y XIV». Este desarrollo se estudia siguiendo la actividad generada por los monasterios de la región, los cuales eran propietarios de grandes extensiones de terreno y de ganado vacuno, a cuyo cuidado estaban siervos vaqueros.

17 A. García critica también determinada orientación estructuralista que aparece en la obra de $M_{18}$. Cátedra, aspecto que ya hemos tratado en páginas anteriores.

18 En Estudios ofrecidos a Emilio Alarcos Llorach (Oviedo: Universidad de Oviedo, 1979), vol. IV, pp. $549-563$ 
El sistema de aprovechamiento de pastos sigue un ritmo trashumante estacional. Durante el sig'o XIV esta situación se va a transformar en sentido negativo para los centros monásticos: tanto los núcleos urbanos como determinados sectores de la nobleza intentarán controlar las tierras de pastos.

El capítulo tercero analiza precisamente el «Desarrollo y consolidación de la nobleza laica durante la segunda mitad del siglo XIV, XV, XVI y XVII\%. Primero serán los Quiñones leoneses, luego los Miranda asturianos quienes logren el control de buena parte de las tierras y el ganado del centro-occidente de Asturias. En ambos casos el sistema económico empleado es el mismo: ganado en aparcería, arriendo de pastos y, sobre todo, el sostenimiento de grandes rebaños de ganado cuidados por criados propios en régimen de trashumancia.

En el capítulo cuarto se estudia «La progresiva decadencia de los Miranda (siglos XVII y XVIII) y la formación de los vaqueiros de alzada como grupo social y económicamente diferenciado», pues el autor considera que ambos hechos están intimamente relacionados. Este capítulo puede considerarse el eje central de toda la investigación ya que en él se presentan y defienden las ideas calves del autor en lo que se refiere a la formación del grupo social vaqueiro.

Un factor que se considera fundamental para esa formación es el crecimiento demográfico que durante el siglo XVI tuvo lugar en toda Europa (y también en Asturias). Como consecuencia de ello, los agricultores roturan y cercan nuevas tierras, lo que va en detrimento de los pastos. Los llamados «vaqueros del Principado» (que pagan derechos por los pastizales a la nobleza) se defienden de esa reducción de terreno (que afecta tanto a las tierras altas como a las medias y bajas) levantando cerramientos sobre los espacios abiertos, surgiendo así, lentamente, el prado de guadaña. El resultado inicial de este proceso (que dura hasta el siglo xvili; es el enfrentamiento directo con la nobleza. En las tierras altas del concejo de Somiedo los lugares habitados por estos incipientes vaqueiros, en los que los cerramientos posibilitan un aprovechamiento importante de hierba, van a dar lugar a la sedentarización de sus habitantes. Sin embargo, en los terrenos que por lo reducido de su extensión, u otros factores, no es posible acumular grandes cantidades de hierba, se hizo inevitable la trashumancia descendente durante los tres o cuatro meses de invierno. Los pueblos «de arriba» son, por tanto, el lugar principal de habitación del vaqueiro.

La extensión de los cerramientos hace posible que adquieran entidad de pueblo los pequeños lugares ya habitados (como el Puerto de Somiedo) y que inicien ese proceso otros que apenas eran más que zonas de pastos o brañas, como La Peral, que no es pueblo a finales del XVl pero sí desde mediados del XVIII. En relación con este surgimiento de los pueblos vaqueiros a partir de la transformación de las antiguas brañas, está la aparición de las que el autor denomina «brañas de pueblos no vaqueiros». Estas últimas serían otro sistema de colonización y defensa de pastos comunales por parte de los pueblos vecinos.

El vaqueiro de alzada surge de ese proceso de levantamiento de cercas, que desemboca en la consolidación de unos núcleos de habitación singulares y en la transformación hacia una explotación más intensiva del ganado. El particular modo de vida vaqueiro va a ver completada su fisonomía con la dedicación a actividades no demasiado bien consideradas, como son la arriería y la trajinería.

Según A. García, el origen de estos vaqueiros no está en razas extrañas, sino en los llamados "vaqueros del Principado» (pastores que cuidan ganado propio y concejil), en la propia mano de obra al servicio de la nobleza ganadera e incluso en algunos vecinos de los pueblos altos, cercanos a los actuales pueblos vaqueiros. 
La progresiva constitución de los vaqueiros como grupo social diferenciado va a dar origen a unas claras relaciones de oposición con respecto a los restantes habitantes de la zona. En primer lugar ambas comunidades compiten por el espacio: «Los vaqueiros se apropian individual o colectivamente de una serie de espacios comunales y baldíos que los vecinos de los pueblos colindantes utilizaban para sus ganados desde siempre» (p. 137). Por otra parte, los cambios de residencia del vaqueiro propiciaban el escamoteo del pago de impuestos y diezmos e incluso de los deberes militares. Esta imagen negativa del vaqueiro quedaba definitivamente perfilada con su dedicación a la arriería, tarea que, pese a ser casi imprescindible (o precisamente por ello) generaba desconfianza, resquemor e incluso odio. No es difícil adivinar que de todo ello surgiera el desprecio y la marginación del vaqueiro y que éste, como respuesta, se inhibiera mayoritariamente de las responsabilidades de los pueblos a los que pertenecía administrativa y espiritualmente.

La culminación del proceso de formación del grupo social vaqueiro tiene lugar a finales del siglo XIX y principios del XX, cuando consiguen acceder a la propiedad (por compra pro indiviso) de todos los terrenos comunales que pertenecían a los pueblos que ocupaban, tanto los de invierno como los de verano.

Hasta aquí el estudio de carácter histórico; la segunda parte de la obra aborda el análisis etnográfico. En el capítulo primero («El nivel de adaptación tecnológico») se hacen diversas consideraciones acerca del medio ecológico habitado por los vaqueiros, la estructura económica.de sus pueblos y el tipo de viviendas. De todo ello destaca el hecho de que la economía vaqueira se articula en torno a unos terrenos cercados y de propiedad privada dedicados a cultivos y a prados de guadaña (en parcelas de reducida extensión) y sobre todo en unas zonas de pastos de propiedad colectiva, que en los pueblos altos alcanzan grandes dimensiones y que son la verdadera clave de su organización económica. Todo ello se complementaba (hasta hace 35 ó 40 años) con la arriería, tarea de especialísima importancia. La situación no era idéntica hace sólo treinta años. Entonces, según el autor, sólo la mitad de los espacios cercados se dedicaban a prados, el resto eran cultivos. Sin embargo, en siglos anteriores parece que el sistema no era el mismo: «A finales del siglo XVI, los habitantes de Perlunes no sembraban absolutamente nada, y el espacio cercado dedicado a prados de guadaña era también muy reducido, a juzgar por la hierba seca que recogían. Los únicos ingresos que obtenían eran producto de la venta de ganado (...) y de la arriería y trajinería» (p. 190).

Toda esta problemática sobre la extensión de los cerramientos nos plantea una serie de dudas. La idea que repite el autor es que el cerramiento de tierras que se inicia en el siglo XVI, y acaba consolidándose en el XVIII, hizo posible la estancia prolongada (8-9 meses) en los pueblos de arriba y al mismo tiempo transformó la economía vaqueira haciéndola evolucionar hacia formas más intensivas, que incluían la práctica de una serie de cultivos que no eran meramente subsidiarios. Sólo en las últimas décadas el aprovechamiento lechero habría llevado a la reducción de cultivos. Sin embargo, pese a lo que acabamos de exponer, el autor no muestra con claridad la importancia económica de los espacios cercados. Asegura que en el siglo xvi son todavía muy escasos (y no sólo en Perlunes), pero hace 30 ó 40 años (cuando el proceso de los cerramientos está ya culminado desde tiempo atrás) su extensión sigue siendo mínima en los pueblos de arriba. Es más, el mismo autor insiste en que lo fundamental ha sido la propiedad y explotación colectiva de los pastos, pues «sin este tipo de propiedades, dadas las dimensiones de los cerramientos y el número de cabezas de ganado, sería inexplicable la entidad del grupo" (p. 193).

Continuando con el análisis de la situación social y económica se hacen referencias al fenómeno de la trashumancia y su transformación durante las últimas décadas. Se 
comenta la importancia de la sedentarización en el proceso de desvaqueirización y se recogen comentarios de vaqueiros sobre el trauma que supone el abandonar la subida a los pueblos de verano y pasar a residir permanentemente en los de invierno. Sin em. bargo, todavía ahora hay cinco pueblos de verano habitados sólo estacionalmente ${ }^{19}$ y además (según el mapa de la página 220) hay otros cinco pueblos, también de verano, que se han convertido en sedentarios ${ }^{20}$. Por tanto, la desaparición de la trashumancia no parece que pueda analizarse exclusivamente en función del asentamiento estable en los pueblos de invierno. Además, cabría estudiar - como en otras cuestiones que apuntaremos- la relación que puede existir entre la desaparición de la trashumancia en esta zona de Somiedo-Belmonte-Salas y la producida en Cangas de Narcea-Tineo-Luarca, ya que en esta última no parece que ningún pueblo de verano de los puertos altos se haya convertido en lugar estante de población ${ }^{21}$.

El apartado dedicado a la vivienda quizá sea el más interesante y el que mayores novedades aporta de toda la segunda parte. A. García critica la falta de precisión y el confusionismo existente en los estudios sobre las habitaciones de las brañas y en general sobre las edificaciones circulares o cuadrangulares con techos de paja, que han sido las más estudiadas. El autor hace dos clasificaciones sobre la evolución de las viviendas, tanto en los pueblos de verano como en los de invierno. Se puede discutir el modelo evolutivo presentado - desde el chozo circular a la casa-establo actual- pero lo cierto es que el análisis realizado es ciertamente clarificador y ordena tipologías que nunca se habían planteado en el registro bibliográfico.

En relación con el tema de la vivienda aparece el problema de las diferencias existentes (tanto en la habitación como en el terreno explotado) entre la zona estudiada por el autor y la de Tineo, Allande y Cangas de Narcea. Muchas de las brañas de alzada de estos concejos o han desaparecido o son propiedad de los pueblos colindantes, «y los restos de sus construcciones nos muestran la existencia de chozos circulares de escasas dimensiones para refugio del pastor» (p. 228), además, tampoco existen cerramientos. Otra diferencia apuntada es la relativa al tipo de poblamiento existente en los pueblos vaqueiros de invierno de la zona de Belmonte y Salas y los de Tineo y Luarca. En los primeros el hábitat se presenta agrupado, mientras que en los segundos las viviendas y sus anexos aparecen muy dispersos y rodeados de terrenos cercados relativamente grandes.

Estas disimilitudes y especialmente las que afectan a los pueblos de verano (con chozas ${ }^{22}$ y ausencia de cerramientos en Tineo, Allande y Cangas) las intenta explicar el autor apuntando que, posiblemente, en algunas zonas (como las citadas) el proceso de expansión de los cerramientos, que considera clave en la formación del grupo social vaqueiro, "se haya retrasado o que nunca haya tenido lugar» (p. 228): De ello deduce que "parece ser un hecho cierto que la formación del vaqueiro de alzada como grupo social diferenciado no siguió un proceso uniforme ni simultáneo en todas las zonas de Asturias en que existieron o existen" (p. 228). La comprobación de este hecho (sobre el que no insiste el autor) es de fundamental importancia desde nuestro punto de vista, ya que de alguna forma cuestiona la hipótesis central del trabajo que comentamos. Queda, por tanto,

19 Perlunes, La Peral, Puerto, La Falguera y Llamardal.

20 La Rebollada, Villar de Vildas, Saliencia y Valle del Lago.

21 Sí ha ocurrido, en parte, en las brañas de alzada del interior, como Los Corros (Luarca) y Bustellán y Las Tabiernas (Tineo).

22 No obstante, en las brañas de alzada todavía existentes en Tineo y Luarca (Las Tabiernas, Bustellán y Los Corros) el tipo de viviendas es totalmente distinto (más complejo) y los cerramientos son la forma típica de ocupación del espacio. 
en el aire, la explicación de las diferencias que, en muy distintas esferas, se observan entre los vaqueiros de las dos zonas a las que nos hemos venido refiriendo. Se hace indispensable un estudio histórico y etnográfico comparativo.

El capítulo segundo de esta segunda parte aborda «La adaptación social del vaqueiro de alzadan. Sin temor a equivocarnos, podemos afirmar que, tanto este capítulo como el siguiente (y último de la obra) no responden totalmente a lo que se puede esperar de un trabajo de campo etnográfico. Ciertamente el estudio de las relaciones familiares y sociales se trata de forma bastante somera, sin insistir en la descripción actual del problema. Si esto queda patente en el apartado dedicado a «la familia o grupo doméstico», es todavía más señalado en el titulado «Los vaqueiros de alzada como grupo social diferenciado». En éste, de muy corta extensión, cabría esperar que se hiciera un detallado análisis del conjunto de situaciones sociales y de relaciones con somedanos y xaldos, que caracterizan la imagen actual de la comunidad vaqueira. Sin embargo, esto se aborda de manera muy superficial (con algún detalle más en las relaciones de parentesco) sustentando la caracterización del grupo vaqueiro casi exclusivamente con referencias históricas que ya se habían presentado en la primera parte del libro.

Algo semejante puede decirse respecto al capítulo tercero ( «La adaptación ideológica de los vaqueiros de alzada»). La hipótesis del autor -típica del materialismo culturales que «la adaptación ideológica viene determinada por su nivel de adaptación tecnológico y social, al tiempo que retroalimenta a los otros dos sistemas parciales o niveles» (p. 293). Creemos que no es especialmente interesante criticar esa postura, porque en la antropología cultural está más o menos aceptada, aunque los idealistas más feroces se opongan rotundamente a ella.

En lo que se refiere al sistema ideológico del vaqueiro, el autor asegura que le ha resultado difícil el acceso al mismo, entre otras razones por la dificultad para obtener testimonios válidos. Además, justifica esta incapacidad con una cita del historiador francés Duby según la cual esa dificultad de acceso existe cuando los grupos sociales estudiados "no han dispuesto por sí mismos de los instrumentos culturales capaces de plasmar en formas duraderas su propia visión del mundo» (p. 296). Ciertamente, puede que la cita de Duby tenga sentido en su contexto pero no creemos que sea aplicable al grupo vaqueiro. Los trabajos de María Cátedra sobre los vaqueiros de Tineo y Luarca han mostrado la existencia de una cosmovisión vaqueira bastante rica y peculiar. A la obra de A. García parece faltarle esa profundidad de análisis etnográfico de la que dan muestra los escritos de M. Cátedra. El propio autor reconoce que lo que ha elaborado es una «atrevida $e$ incompleta reconstrucción del sistema de adaptación ideológico o actitudes mentales del grupo vaqueiro» (p. 296), además dispone de un «escaso y disperso material». Por todo ello concluye que «no hemos podido descubrir ningún dato mediante el trabajo de campo que nos dé pie a hablar de una cosmovisión vaqueira que vaya más allá de estos niveles ecológicos y sociales» (p. 296). No obstante, también podríamos apuntar que la casi veintena de años transcurridos desde los primeros estudios de María Cátedra se han dejado notar sensiblemente en el cambio de las condiciones de vida materiales, y seguramente espirituales, de los vaqueiros. Estas transformaciones pueden haber afectado con mayor intensidad a los vaqueiros de la zona estudiada por A. García - Somiedo, Salas y Belmonte- por su menor número, frente a los que habitan los concejos de Tineo y Luarca, pese a que éstos se hayan sedentarizado más tempranamente.

Con las limitaciones que venimos apuntando, y que el mismo autor reconoce, parece evidente que ha sido escaso el grado de profundización en el tema. Se hacen referencias a la dualidad espacio-temporal de pueblos de verano-pueblos de invierno, a determinados valores de conducta, a las antiguas fiestas de Carnaval, a «algunos ritos de paso», «brujería 
y magia" y la actitud del vaqueiro ante la religión oficial. El análisis de la situación actual de los vaqueiros (sea cual fuere el grado de transformación de los rasgos culturales tradicionales) queda sin tratar, dando una imagen totalmente diluida de la comunidad vaqueira en el momento presente.

El trabajo de A. García se completa con nueve apéndices documentales que recogen otros tantos textos de los siglos $\mathrm{XV}$ al XIX referentes a la comunidad vaqueira.

Llega el momento de concluir este extenso comentario bibliográfico. Creemos que han resultado patentes las diferentes orientaciones, metodologías e intereses que han guiado a los dos autores reseñados. La línea de María Cátedra se enmarca absolutamente en un enfoque antropológico-social preocupado por la descripción e interpretación sociológica de una comunidad marginada, en el momento actual. Las referencias históricas son mínimas y se acude a ellas para criticar errores del pasado o para comprobar en ese registro algunos hechos del presente. Sin embargo, no se trabaja con material de archivo y esto impide a la autora comprobar de manera cierta cuál ha sido el proceso de formación de la comunidad vaqueira y la transformación de sus rasgos culturales hasta el momento presente. Por otra parte, al no incidir (salvo apartados concretos) en la comparación con otros ganaderos y agricultores del occidente asturiano, no hay posibilidad de ver si son ciertamente propios y particulares los elementos culturales que se atribuyen a los vaqueiros, o cómo se ha producido el trasvase de los mismos. En cualquier caso, insistimos en que el grado de identificación de la vida y la mentalidad vaqueira es muy alto y habrá pocos casos de escritos etnográficos de la Península que lleguen a su nivel.

La obra de A. García, por el contrario, representa un serio intento por interpretar la realidad vaqueira conjugando la interpretación histórica y el análisis etnográfico. Sus limitaciones y problemas, así como los logros, ya han sido expuestos y no vamos a insistir en ellos. Eso sí, queremos hacer referencia a una cuestión que consideramos fundamental (junto con el problema de los cerramientos) y que sólo ha sido abordada de manera muy parcial por el autor. Se trata del origen social y poblacional de los primeros vaqueros de los que surgen los que conocemos como vaqueiros de alzada. Para A. García estos individuos serían mayoritariamente los que se nombran en los documentos como «vaqueros de Asturias» o "vaqueros del Principado», que son vecinos que «desde concejos del interior o de la costa, subían a estos pastos altos al cuidado de ganado propio, del de otros vecinos y hasta tal vez propio del concejo» (p. 89). El autor no da más explicaciones sobre esto y tampoco queda claro por qué de ellos surge la comunidad vaqueira mientras que las brañas de los pueblos no vaqueiros (constituidas de forma contemporánea) siguen siendo sólo eso, brañas no vaqueiras. Para explicar convenientemente este problema habría que profundizar en la línea apuntada por A. García, estudiando fundamentalmente el fenómeno de la trashumancia desde la Edad Media.

Por otra parte, dadas las didferencias que tanto en el registro histórico como en el etnográfico aparecen entre los vaqueiros de Somiedo-Belmonte-Salas y los de Cangas de Narcea-Tineo-Luarca, sería necesario el estudio histórico detallado de estos últimos y una investigación etnográfica más profunda sobre los primeros. En realidad, lo más conveniente sería proceder a un estudio por extenso de la comunidad vaqueira, localizar de manera precisa sus lugares de habitación en todos los concejos tradicionalmente vaqueiros ( $\mathrm{y}$ en los que pudieran haberlos acogido en algún momento de la historia) y realizar un pormenorizado análisis histórico y etnográfico de todos ellos ${ }^{23}$. Se ha escrito mucho (aunque

23 Francisco Feo Parrondo, en su trabajo de 1986 (citado en nota 2) hace un acercamiento geográfico a esta cuestión. Sus aportaciones más interesantes se refieren a los aprovechamientos 
no con demasiada calidad) sobre los vaqueiros pero todavía no se ha abordado un estudio como el que proponemos, que, sin lugar a dudas, ofrecería bases inás seguras para la comprensión de esta comunidad y de toda la sociedad rural del occidente asturiano.

\section{LUIS ÁNGEL SÁNCHEZ GÓMEZ}

CSIC, Madrid

agrícolas y ganaderos en las brañas. Ofrece igualmente un análisis estadístico de la población de algunas de éstas. No obstante, no se explica el procedimiento seguido para la cuantificación ni se tratan de identificar la totalidad de las brañas vaqueiras, decidiéndose por aceptar la existencia de unos determinado concejos vaqueiros siguiendo criterios de otros autores que no son criticados ni valorados debidamente. En cualquier caso, la información original presentada no es muy abundante, pues la mayor parte del trabajo es una sintesis de obras anteriores. 